almost always psychiatric ? How many are contained among the 26,884 men and 1,905 women, homeless and single, who were discovered by the recent survey of the National Assistance Board ${ }^{5}$ to be sleeping in 550 lodging-houses, hostels, and shelters, or among the 1,000 and more who were "sleeping rough" ? Similarly, what would a more detailed analysis of the estimated $12 \%$ mentally ill people among the residents in common lodging-houses in Edinburgh show ? 7 Again, what percentage are represented in the ever-increasing number of persons of "no fixed abode" admitted to mental hospitals ? ${ }^{8}$ All these questions need to be answered before any claim to the reduction of the mentally ill in absolute terms can be made.

Miss Brooke's census is nevertheless a prodigious effort, and it is regrettable but not surprising that its period of gestation was over three years. The mass of factual detail in it will engross medical and social historians for years to come. Certain data are particularly pertinent. Thus, there were 51,616 residents aged 65 and over in mental illness hospitals and units, representing $39 \%$ of all resident patients and one in every 109 people in this age group in the general population of England and Wales. As things are, the number of such old people to be cared for somewhere must go on increasing. What accommodation for most of them is available other than in mental hospitals ?

Miss Brooke points out that only 2,781 patients are being treated in units in non-psychiatric hospitals, compared with 123,744 in the ordinary mental hospitals, but they were occupying 4 out of 5 available beds. The under-utilization of these beds, incidentally, is as worthy of inquiry as the surprisingly low $61 \%$ occupancy of beds in aftercare hostels reported in a Ministry of Health survey. ${ }^{9}$

There are 932 teaching-hospital beds in all for psychiatric cases, of which 750 are in London. Miss Brooke rightly emphasizes that even for short-term patients these teaching units are carrying a much smaller proportion of schizophrenics than regional board hospitals and units, where they form by far the largest group. She goes on to point out " that recognized schizophrenics may be likely to have readmissions to regional board hospitals instead of being readmitted to teaching units."

From these data is it possible to foresee the future of the older type of mental hospitals? Are they fated to become living graveyards for increasing numbers of senile patients and the repositories of what are euphemistically called "longstay" schizophrenics? If this is so, surely social chaos would follow their destruction.

\section{Intestinal Obstruction by Food}

Once in a while a patient operated on for intestinal obstruction is found to be blocked by a mass of food residue, usually in the ileum. This is known to be more likely in the edentulous, who bolt their food, and in the gastrectomized, who may pass on balls of indigestible matter without the benefit of maceration by the antrum. F. O. Stephens ${ }^{1}$ has done a useful service in listing the foods which have been reported to impact in the intestines. Some are conventional enough-orange-pith and lumps of meat will surprise no one-but his roll-call of incriminated foods is a bizarre one. Apparently the first case report was of small intestinal

'Stephens, F. O., Gut, 1966, 7, 581. obstruction by 909 cherry stones. The list, in alphabetical order, quickly reveals " ammunition bread" and, shortly after, Christmas pudding. Locusts have caused obstruction, and so also have grasshoppers. Most vegetables, fruits, and stones are incriminated, and to those embarking on the brain drain a word of warning-popcorn has occluded someone's ileum. Tripe has a bad reputation, and visitors to exotic places may be daunted by the knowledge that turtle eggs are also specified on the list. Perhaps the Victorians were right after all-we should chew each mouthful thirty-two times.

Does this carry any message for the surgeon faced by a patient with intestinal obstruction? The answer seems to be that only in patients who have previously had a gastrectomy and perhaps are also edentulous can a tentative preoperative diagnosis be made. If they have recently consumed oranges or cabbage conservative treatment may be worth while, and the bolus will sometimes pass. It must be emphasized that this will be a rare event in any surgeon's working life.

\section{Screening for Cervical Cancer}

With the advent of cytological examination of cervical smears on a large scale has come the hope that cancer of the cervix might be eradicated. T. N. Roman and J. P. A. Latour, ${ }^{1}$ in Montreal, showed that the proportion of women with invasive carcinoma of the cervix surviving five years rose from $41 \%$ in $1943-7$ to $71 \%$ in $1953-7$. This improvement, which they attribute to the progressive intensification of cytological screening in the past 20 years, was accompanied by an increase in the number of cases diagnosed at an early stage. The incidence of stage I carcinoma of the cervix rose from $41 \%$ to $61 \%$. Since efforts have been made to distinguish between preclinical and clinically obvious invasive carcinoma of the cervix, there is also evidence that the diagnosis is being made earlier within stage I, for over ten years the five-year survival rate rose from $56 \%$ to $88 \%$.

Undoubtedly the early diagnosis of carcinoma of the cervix improves the prognosis, but it is difficult to be sure that the detection of carcinoma-in-situ is having much influence on the eradication of invasive carcinoma of the cervix. In this respect the results of routine cytological screening have been somewhat disappointing, for despite the detection of large numbers of women with preinvasive lesions the overall incidence of carcinoma of the cervix has remained virtually unchanged. ${ }^{2}$ This has led some workers to suggest that there may be at least two different forms of carcinoma of the cervix $^{3}$; the first progresses slowly to invasion of the underlying tissues through a preinvasive phase, while the second is rapidly progressive, may not be preceded by carcinomain-situ, and (no matter how prompt the diagnosis or how radical the treatment) has a relatively bad prognosis. Nevertheless, even if this point of view were correct, the large amount of effort involved in cervical screening could still be

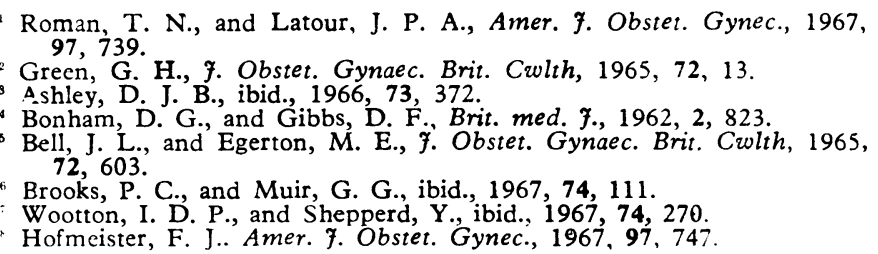

Roman, T. N., and Latour, J. P. A., Amer. 7. Obstet. Gynec., 1967, 97, 739.

Green, G. H., 7. Obstet. Gynaec. Brit. Cwlth, 1965, 72, 13

Ashley, D. J. B., ibid., 1966, 73, 372.

Bonham, D. G., and Gibbs, D. F., Brit. med. f., 1962, 2, 823

Bell, J. L., and Egerton, M. E., $\dddot{f}$. Obstet. Gynaec. Brit. Cwlth, 1965, 72,603 .

Rrooks, P. C., and Muir, G. G., ibid., 1967, 74, 111

Wootton, I. D. P., and Shepperd, Y., ibid., 1967, 74, 270

Hofmeister, F. J.. Amer. F. Obstet. Gynec., 1967, 97, 747. 
justified on two grounds. Firstly, women would benefit from the earlier detection of invasive lesions, and, secondly, doctors would gain a better understanding of the natural history of cervical cancer.

The introduction of routine screening of the cervix for cancer brings with it many other problems. Not the least of them is finding a method that is suitable for practical application on a large scale. The size of the task created by the nation-wide screening of women is overwhelming and a burden that cannot be carried with the aid of methods and resources at present available. Even if it were possible to collect the specimens in requisite numbers, there are insufficient technicians to process and scan the cervical smears. Nevertheless, a comprehensive service of this sort could not afford to reduce its load, or justify doing so, by eliminating a large and most important group of women on age alone. Though the incidence of carcinoma-in-situ in women between the ages of 20 and 30 is lower than in older women, it is still about $3-4$ per 1,000 , as Dr. J. T. Boyd and his colleagues point out at p. 785 of this week's B.M.F.

The hopes that were raised when D. G. Bonham and D. F. Gibbs $^{4}$ introduced a histochemical test for detecting increased quantities of the enzyme 6-phosphogluconate dehydrogenase in the vaginal fluid of women with carcinoma of the cervix have gradually faded. ${ }^{5}$ The careful comparison of the results of screening by cytological and enzyme tests presented by Boyd and his colleagues shows convincingly that little will be gained by pursuing the application of enzyme detection on a large scale. Despite reports ${ }^{6} 7$ that the estimation of 6phosphogluconate dehydrogenase activity in vaginal fluid may be used to detect invasive cervical cancer, its reliability - is far below that of cytology for the detection of carcinomain-situ.

Boyd and his colleagues have also highlighted another of the problems encountered in large-scale routine screening for cervical cancer-namely, the reluctance of women to accept this service even when it was offered freely and under conditions that must have caused them very little inconvenience. Of even greater importance is that they have confirmed that it is the women who are at greatest risk from cervical cancer who are the most reluctant to participate in a survey of this sort. Probably fear and ignorance are important factors in this respect. Though routine screening for cervical cancer cannot yet be offered to every woman in Britain, it is important that the problem of education should be tackled now. This is not just a problem, however, of educating the publicsome doctors also have yet to be convinced of the value of routine screening. As F. J. Hofmeister ${ }^{8}$ has emphasized, education for carrying out cervical screening programmes must begin with the doctors, and, before that, with medical students.

\section{Dopa and Parkinsonism}

Despite the multiplicity of proprietary drugs recommended for the treatment of Parkinsonism, clinical results are generally disappointing. Most of the available preparations contain natural or synthetic alkaloids of the solanaceous family. While dramatic improvement is rare, undesirable side-effects, including dryness of the mouth, impaired visual accommodation, and toxic confusional states are all too frequent.
A possibly more promising therapeutic approach may stem from current studies of the relationship between certain aromatic amino-acids and melanogenesis. Brains from patients with Parkinsonism have less melanin than normal in the substantia nigra ${ }^{1}$ and also depleted stocks of biogenic amines in the substantia nigra and the corpus striatum. ${ }^{2}$ Dihydroxyphenylalanine (dopa) may provide a further biochemical clue, for in both melanocytes ${ }^{3}$ and sympathetic cells $^{4}$ tyrosine is hydroxylated to dopa, which is a common precursor of both melanin and catecholamines. Ingenious attempts to improve the faded appearance of cells of the substantia nigra in patients with Parkinsonism by giving melanocyte-stimulating hormone increased the pigmentation of the skin but aggravated the symptoms of the disease. This unexpected result suggested that the hormone was shunting dopa from brain stem to skin and aroused interest in the therapeutic possibilities of this substance. At first some improvement of patients with Parkinsonism was found when they received dopa, but this finding was later disputed. $^{78}$ Recently higher doses of dopa (3-16 g. daily by mouth) are reported by G. C. Cotzias and colleagues to have provoked striking and sustained improvement. ${ }^{5}$ Repeated trials of DL-dopa in the treatment of sixteen patients with Parkinsonism provoked either complete disappearance or considerable amelioration of disabilities in eight of them. Improvement in tremor, cogwheel movements, rigidity, muscular weakness, festination, and salivation were all recorded. As the dose was gradually increased improvement was first noticed in rigidity, and only at higher levels was improvement in tremor observed. One patient, greatly disabled by mental confusion and refractory to conventional drugs, showed a particularly striking improvement. Another, who showed marked improvement of power and tremor, developed euphoria, exaggerated facial expression, and florid gesticulations. Involuntary movements of the tongue developed in one patient and moderate athetoid movements of all limbs in another. The "drugged" and sleepy effects associated with most anti-parkinsonian drugs were notably absent. It is curious that the most impressive improvement occurred in patients with advanced disease and that four of the patients who failed to respond had only mild unilateral disabilities. The eight patients who had improved on DL-dopa were subsequently given its precursor, DL-phenylalanine; none benefited, and most became worse.

Four patients developed reversible granulocytopenia during treatment with DL-dopa. Occasional atypical mononuclear cells were seen in the peripheral blood, and examination of the bone marrow showed intracellular vacuoles in cells of the myeloid series.

Cotzias and colleagues, ${ }^{5}$ noting that the conversion of phenylalanine to dopa requires hydroxylation, have suggested that defective hydroxylation may prove to be a fundamental error in Parkinsonism. The relatively mild haematological abnormalities must impose caution in using this treatment, but further studies will be awaited with considerable interest.

\footnotetext{
Duffy, P. E., and Tennyson. V. M., f. Neuropath. exp. Neurol., 1965, 24, 398.

Hornykiewicz, O., Wien. klin. Wschr., 1963, 75, 309

${ }^{3}$ Fitzpatrick, T. B., Seiji, M., and McGugan, A. D., New Engl. 7. Med., $1961,265,328$.

- Udenfriend, S., Pharmacol. Rev., 1966, 18, 43.

Cotzias, G. C., Van Woert, M. H., and Schiffer, L. M., New Engl. 7. Med., 1957, 276, 374.

'Birkmeyer, W., and Hornykiewicz, O., Arch. Psychiat. Nervenkr. $1962,203,560$.

McGeer, P. L., and Zeldowicz, L. R., Canad. med. Ass. F., 1964, 90, 463.

"Fehling, C., Acta neurcl scand., 1966, 42, 367.
} 